\title{
Review Article \\ Effect of Metformin Intervention during Pregnancy on the Gestational Diabetes Mellitus in Women with Polycystic Ovary Syndrome: A Systematic Review and Meta-Analysis
}

\author{
Zhihong Zhuo, ${ }^{1,2}$ Aiming Wang, ${ }^{3}$ and Huimin $\mathbf{Y u}^{2}$ \\ ${ }^{1}$ Southern Medical University, Guangzhou 510000, China \\ ${ }^{2}$ Ningbo No. 2 Hospital, Ningbo 315010, China \\ ${ }^{3}$ Navy General Hospital of Chinese PLA, Beijing 100000, China \\ Correspondence should be addressed to Aiming Wang; one_army@sina.com
}

Received 22 March 2014; Revised 20 April 2014; Accepted 23 April 2014; Published 21 May 2014

Academic Editor: Raffaele Marfella

Copyright (c) 2014 Zhihong Zhuo et al. This is an open access article distributed under the Creative Commons Attribution License, which permits unrestricted use, distribution, and reproduction in any medium, provided the original work is properly cited.

\begin{abstract}
Metformin is an effective insulin sensitizer treating type 2 diabetes mellitus. However, the functional consequences of metformin administration throughout pregnancy on gestational diabetes mellitus (GDM) with polycystic ovary syndrome (PCOS) have not been assessed. We therefore performed a meta-analysis and system review to determine the effect of metformin on GDM in PCOS. A meta-analysis was performed on the published studies before December, 2013. Meta-analysis examined whether metformin could reduce GDM occurrence in PCOS with a fixed effect model. The odds ratio (OR) with 95\% confidence interval (95\% CI) was calculated to estimate the strength of association. A total of 13 studies including 5 RCTs and 8 non-RCTs were enrolled. Ultimately, effectiveness analysis demonstrated that, in total, there was no significant availability of metformin on GDM in PCOS in contrast to placebo (OR $=1.07,95 \%$ CI $0.60-1.92)$ in RCTs and significant availability of metformin on GDM (OR $=0.19,95 \%$ CI $0.13-0.27)$ was indicated in non-RCTs. In summary, according to the results of our meta-analysis, strictly, metformin did not significantly effect on GDM with PCOS, though more multicenters RCTs still need to be investigated.
\end{abstract}

\section{Introduction}

Polycystic ovarian syndrome (PCOS), which is one of the common endocrine disorders, is one of the main causes of ovulatory infertility, affecting $5-10 \%$ of women of reproductive age $[1,2]$. PCOS is characterized by the presence of typical ultrasound features of polycystic ovaries, oligomenorrhea, and clinical and/or biochemical hyperandrogenism and, commonly, by insulin resistance, hyperinsulinemia, morbid obesity, and infertility [3-9]. Insulin resistance appears in both obese and nonobese women with PCOS [10]. Among these women, insulin promotes intraovarian steroidogenesis by interacting with luteinizing hormone (LH) leading to inappropriate advancement of granulose cell differentiation and arrest of follicle growth. The outcomes with hyperinsulinemia may directly enhance ovarian secretion and abnormal follicular development, which ultimately lead to ovarian dysfunction [11, 12]. Moreover, hyperinsulinemia has been suggested as pathogenic factors in pregnancy complications [6]. Insulin resistance or obesity with PCOS leads to a significant increase in gestational outcomes and difficulties during labor.

During recent years, metformin, which is an effective oral biguanide insulin sensitizer, has been widely used for treating type 2 diabetes mellitus (T2DM) as an antihyperglycemic agent [13], by improving tissue sensitivity to insulin while inhibiting hepatic glucose production, enhancing peripheral glucose uptake, and decreasing insulin levels [14, 15], and approved by the United States Food and Drug Administration (FDA) [16]. Therefore, metformin has become an ideal first line therapy for individuals with T2DM. When treated in women with PCOS, especially these patients with hyperinsulinemia, metformin corrects hyperinsulinemia and also reduces ovarian androgens, $\mathrm{LH}$ and sex hormone binding globulins. Metformin has been increasingly regarded to be effective and safe medicine for the metabolic and endocrine 
abnormalities in PCOS $[17,18]$. Its use as a drug for ovulation induction in PCOS has been extensively investigated and has been found to increase the likelihood of ovulation and decrease miscarriage rates, particularly in patients who have clomiphene resistance before. As we all know, metformin is a category B drug for use in pregnancy (absence of teratogenic effects based on animal data) and its characteristics of effectiveness and safety and, as a result, its use in pregnancy have become increasingly popular worldwide, although there are no guidelines for its continuous use in pregnancy and there is debating on potential adverse effects on both the mother and the fetus because of its crossing the placenta $[19,20]$.

Moreover, metformin has been considered as a potentially effective agent during pregnancy to treat gestational diabetes mellitus [21]. On the other hand, several randomized controlled trials (RCTs) evaluating the reproductive effect of metformin administration and reporting the occurrence of GDM are not available in literatures. Experimental and clinical studies seem to suggest that metformin does not have any effect on the incidence of GDM in women with PCOS. Furthermore, unclear and nonpowered data support the use of metformin for the prevention of GDM, preeclampsia, and other gestational complications in PCOS patients [22].

Based on these considerations, we conducted a systematic review and meta-analysis of trials for a more objective appraisal of evidence regarding the effect of pregestational metformin administration on gestational complications, especially the gestational diabetes in women with PCOS.

\section{Materials and Methods}

A systematic review was conducted with all pertinent studies that were found in the electronic databases MEDLINE, EMBASE, and the Cochrane Central Register of Controlled Trials (CENTRAL) that examined metformin and pregnancy outcome on the women with PCOS from 1966 to December, 2013. The search strategy included the terms pregnancy, pregnant complication, GDM, gestational diabetes mellitus, diabetes, metformin, biguanide, insulin-sensitizing drugs, insulinsensitizers, polycystic ovary syndrome, and PCOS. The search was concluded by (1) the perusal of the reference sections of all relevant studies in all languages and (2) a manual search of the key journals and abstracts from the major annual meetings in the fields of endocrinology and obstetrics and gynecology. Articles were excluded from the analysis if they did not have either adequate disease-matched control groups or data on the outcome of the pregnancy with respect to major gestational diabetes and exposure to metformin throughout pregnancy or in at least the first trimester. The control groups consisted of women with PCOS who were not treated with metformin or placebo.

The inclusion and exclusion criteria were as follows.

Inclusion criteria:

(1) PCOS was exposed to metformin throughout the pregnant period, or at least during first trimester;
(2) studies could be a prospective, retrospective, or a case-control study; however, there had to be a control group;

(3) studies were written in any language.

Exclusion criteria:

(1) if type of articles was review or letter to the editor;

(2) animal studies;

(3) studies with no control group or with an inappropriate control group;

(4) women with exposures to other known pathogenic factors or other maternal disorders that might affect the outcome.

Titles and, especially, abstracts were screened, and the potential relevant researches were identified. Two independent reviewers (ZHUO and YU), who were not blinded to the names of investigators or sources of publications, identified and selected the articles that met the inclusion and exclusion criteria below. The reviewers worked independently and in duplicate. Disagreements between two of them were resolved by consensus or arbitration between each other. Meta-analysis was conducted using Review Manager 5.2 software (Review Manager (RevMan) (computer program) (Version 5.2 for Windows), Oxford, England: The Cochrane Collaboration, 2012).

We included trials evaluating the reproductive effects of metformin administration on the gestational complications especially GDM in the women with PCOS in the current meta-analysis. We considered all studies in which the diagnosis of PCOS was based on the normal criteria such as Rotterdam ESHRE/ASRM consensus criteria, NIH criteria, or AES criteria eligible.

The quality of the studies included was evaluated by the Cochrane guidelines [23]. Specifically, allocation concealment, blinding, intention-to-treat (ITT) analysis, and followup were assessed for each trial. Allocation concealment was graded as adequate (A), unclear (B), or inadequate (C) according to the criteria provided by the Cochrane Group [24] particularly. Blinding was reported as yes, no, or not reported for patients, outcome assessors, investigators, or data analysts. The use of ITT analysis was recorded and indicated as yes or no.

The Q-test of Cochran RevMan was used to measure the heterogeneity between articles and was calculated as the weighted sum of squared differences between individual study effects. A Cochran $Q$-test $P \leqslant 0.05$ represents a statistical homogeneity. For data with statistical homogeneity, the Mantel-Haenszel method was used to calculate the weighted summary RR under the fixed effects model. On the other hand, the random-effect model of meta-analysis was used in the presence of unexplained statistical heterogeneity. $P \leqslant 0.05$ of $95 \%$ CI not containing $1.0 \mathrm{RR}$ was considered statistically significant. 


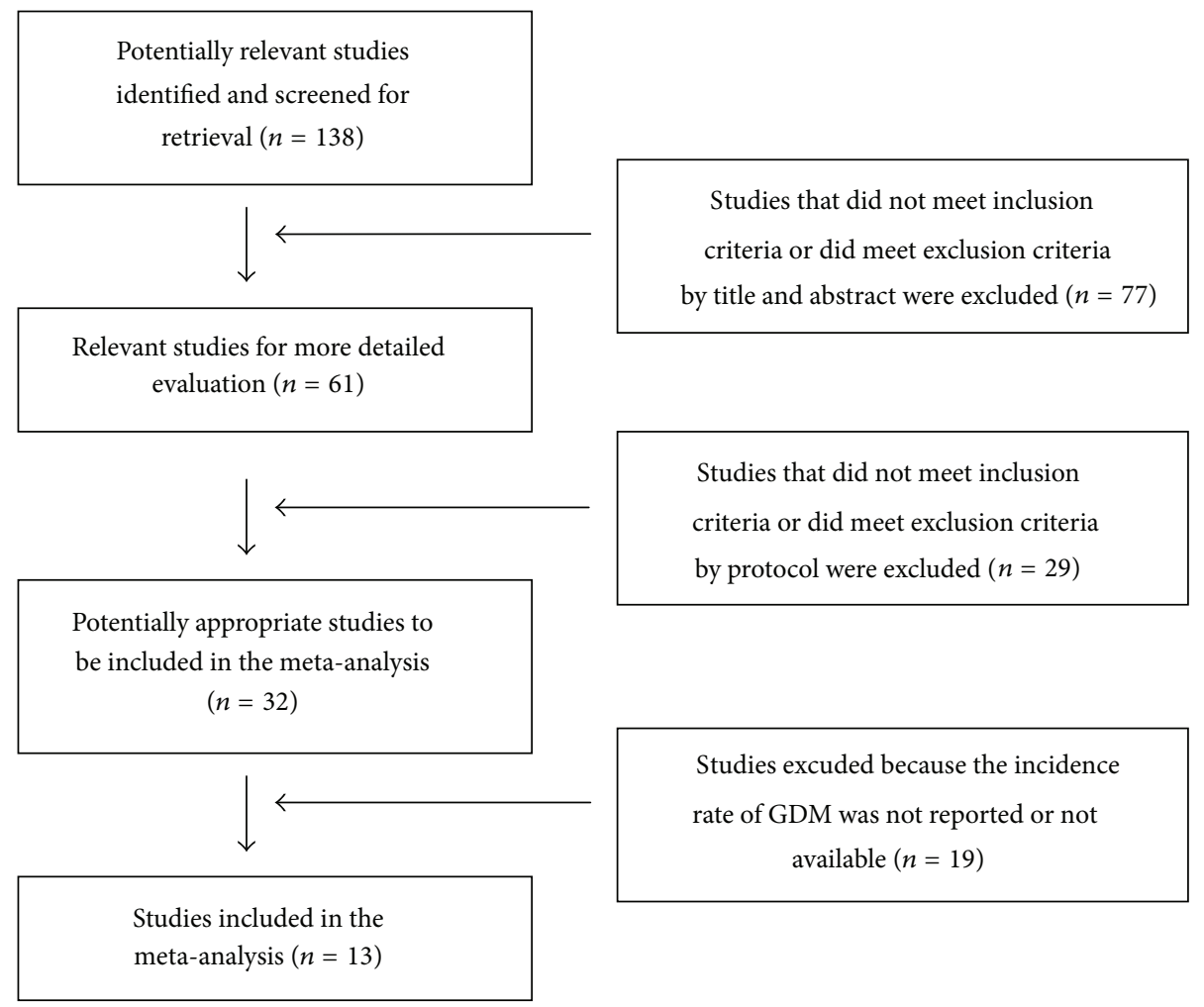

Figure 1: Flowchart of the study selection.

\section{Results}

3.1. Flowchart of Study Selection. The flowchart of the study selection according to the inclusion and exclusion criteria above is shown in Figure 1. A total of 13 trials potentially resulted for inclusion in the meta-analysis [22, 25-36]. In particular, we excluded the trials as follows: the data on the occurrence of GDM were not available from papers and could not be obtained from the investigators by e-mail contact; it was not possible to contact the corresponding investigators and the occurrence rate of gestational diabetes has not been evaluated.

3.2. Characteristics of Studies. Table 1 summarizes the quality of the trials included in the analysis. The main characteristics of the populations, the interventions received, and the outcomes obtained in the trials are summarized in Tables 2 and 4, respectively. A total of five RCTs were also included in the final analysis as Table 3. However, three RCTs including Fougner et al. [30], Vanky et al. [32], and Salvesen et al. [35] are duplicate, and Vanky et al. [22] reported an epianalysis of two randomized controlled trials as Vanky et al. [32] and Salvesen et al. [35]. Finally, we reviewed two RCTs [32, 35] in our meta-analysis. No research included in the system review and meta-analysis had occurrence of gestational diabetes as a primary end point, and none was powered to detect differences in GDM incidence. In addition, other potential gestational complications, such as miscarriage, preeclampsia, and preterm delivery, including the infants' characteristics, were investigated in these studies. The populations studied in the different trials were heterogeneous for several demographic and biochemical/metabolic characteristics.

3.3. Meta-Analysis. 13 studies met the inclusion criteria, including 5 random control trial studies in the calculation of overall GDM occurrences. Exposure to metformin throughout the pregnancy was not associated with a decreased rate of GDM occurrence. The OR for GDM in RCTs with 289 subjects was 1.07 (95\% CI $0.60-1.92, P=0.89$, and $I^{2}=0 \%$ ) (Figure 2) (Fougner et al. [30] and Selvesen et al.s studies [35] were eliminated but Vanky et al's study [32] was enrolled because of the same object of three RCTs; meanwhile, Vanky et al's study [22] was eliminated because of the fact that it is an epianalysis of Vanky et al. [26] and Vanky et al. [32]); inversely, the OR including the studies with disease-matched controls or patient self as control was 0.19 (95\% confidence interval (CI), 0.13-0.27, $P=0.48, I^{2}=0 \%$ ) (Figure 3). Subanalysis was conducted to separate studies into those with PCOS and those with patients' selves with PCOS subjects as controls (Figures 4 and 5, resp.). With 457 subjects in the treatment group, the OR for the nondiabetes pregnancy subjects group was 0.17 (95\% CI, 0.11-0.27, $P=0.40, I^{2}=$ $2 \%)$. With 118 subjects in the treatment group for PCOS with self as control, the OR was 0.24 (95\% CI, 0.11-0.54, $P=0.29$, and $I^{2}=11 \%$ ).

\section{Discussion}

In our mind, this is the first systematic review and metaanalysis of trials including RCTs performed to establish the 
TABLE 1: Metformin studies included in the meta-analysis.

\begin{tabular}{|c|c|c|c|c|}
\hline Number & Authors & Author study type & $\begin{array}{c}\text { Data } \\
\text { collection }\end{array}$ & Malformation described \\
\hline 22 & Vanky et al., 2012 [22] & CO (RCT with placebo) & $\mathrm{P}$ & No description. \\
\hline 25 & Khattab et al., 2011 [25] & $\mathrm{CO}$ & $\mathrm{P}$ & $\begin{array}{l}\text { No miscarriages or neonatal loss } \\
\text { occurred in either group. } \\
\text { One baby girl born with major birth } \\
\text { defect (tracheoesophageal fistula). }\end{array}$ \\
\hline 26 & Vanky et al., 2010 [26] & CO (RCT with placebo) & $\mathrm{P}$ & $\begin{array}{l}\text { Metformin group: one postpartum } \\
\text { pulmonary embolism, one postpartum } \\
\text { circulatory shock, one peripartum } \\
\text { cardiomyopathy, and one sudden infant } \\
\text { death. } \\
\text { Placebo group: three spontaneous } \\
\text { abortions, ileus in one patient with } \\
\text { former gastric bypass operation, and one } \\
\text { perinatal infant death caused by serious } \\
\text { asphyxia. }\end{array}$ \\
\hline 27 & $\begin{array}{c}\text { Nawaz and Rizvi, } 2010 \\
\text { [27] }\end{array}$ & $\mathrm{CC}$ & $\mathrm{P}$ & No description. \\
\hline 28 & Begum et al., 2009 [28] & $\mathrm{CO}$ & $\mathrm{P}$ & No description. \\
\hline 29 & Nawaz et al., 2008 [29] & $\mathrm{CC}$ & $\mathrm{P}$ & $\begin{array}{l}\text { No stillbirths, perinatal deaths, or major } \\
\text { birth defects. One baby in group A had } \\
\text { polydactyl. }\end{array}$ \\
\hline 30 & $\begin{array}{l}\text { Fougner et al., } 2008 \\
{[30]}\end{array}$ & CO (RCT with placebo) & $\mathrm{P}$ & No description. \\
\hline 31 & Glueck et al., 2008 [31] & $\mathrm{CO}$ (self as control) & $\mathrm{P}$ & $\begin{array}{l}\text { No maternal lactic acidosis and no } \\
\text { maternal or neonatal hypoglycemia. Of } \\
\text { the } 180 \text { live births to } \\
\text { the } 142 \text { nondiabetic women with PCOS, } \\
\text { there was one major birth defect } \\
\text { (sacrococcygeal teratoma), as determined } \\
\text { by pediatricians without knowledge of } \\
\text { metformin dose or duration. }\end{array}$ \\
\hline 32 & Vanky et al., 2004 [32] & CO (RCT with placebo) & $\mathrm{P}$ & No description. \\
\hline 33 & Glueck et al., 2004 [33] & $\mathrm{CO}$ (self as control) & $\mathrm{P}$ & $\begin{array}{l}\text { No maternal lactic acidosis or maternal } \\
\text { hypoglycemia; no major birth defects; } \\
\text { there have been no congenital defects or } \\
\text { evidence of intrauterine growth. Seventy } \\
\text { of the } 84 \text { fetuses have had a favourable } \\
\text { outcome; no cases of neonatal } \\
\text { hypoglycemia. }\end{array}$ \\
\hline 34 & Glueck et al., 2002 [34] & $\mathrm{CO}$ & $\mathrm{P}$ and $\mathrm{R}$ & $\begin{array}{l}\text { None developed lactic acidosis. } \\
\text { Intermittent diarrhea or gastritis was } \\
\text { common in the first } 3 \text { weeks of } \\
\text { metformin therapy but resolved } \\
\text { spontaneously and was not limiting } \\
\text { factors. No major fetal malformations or } \\
\text { fetal hypoglycemia occurred. }\end{array}$ \\
\hline 35 & $\begin{array}{c}\text { Salvesen et al., } 2007 \\
{[35]}\end{array}$ & CO (RCT with placebo) & $\mathrm{P}$ & No description. \\
\hline 36 & Hameed et al., 2011 [36] & $\mathrm{CO}$ & $\mathrm{P}$ & $\begin{array}{l}\text { delivered spontaneously at } 33 \text { weeks } \\
\text { gestation with } \\
\text { neonatal asphyxia due to respiratory } \\
\text { distress syndrome and } \\
\text { died } 2 \text { days later. }\end{array}$ \\
\hline
\end{tabular}


TABLE 2: Characteristics of trials in the meta-analysis.

\begin{tabular}{|c|c|c|c|c|}
\hline Number & Population & Intervention & Comparison & Relevant outcomes \\
\hline 22 & $\begin{array}{l}313 \text { singleton pregnancies in } \\
\text { women aged } 18-45 \text { years with } \\
\text { PCOS (Rotterdam criteria). }\end{array}$ & $\begin{array}{l}\text { Metformin ( } 850 \mathrm{mg} \text { twice daily } \\
\text { or } 1000 \mathrm{mg} \text { twice daily), } n=153 \text {. } \\
\text { Age } 29.5 \pm 4.4 \text {, BMI } 29.8 \pm 7\end{array}$ & $\begin{array}{l}\text { 160 PCOS. } \\
\text { Age } 29.1 \pm 4.3 \\
\text { BMI } 28.6 \pm 7.3\end{array}$ & $\begin{array}{l}\text { Second-trimester } \\
\text { miscarriage, preterm } \\
\text { delivery, preeclampsia, and } \\
\text { gestational diabetes. }\end{array}$ \\
\hline 25 & $\begin{array}{l}360 \text { nondiabetic PCOS patients } \\
\text { (Egypt) (Rotterdam criteria) } \\
\text { included were taking metformin for } \\
3-6 \text { months before they became } \\
\text { pregnant. }\end{array}$ & $\begin{array}{l}200 \text { pregnant women continued } \\
\text { on metformin at a dose of } \\
1000-2000 \mathrm{mg} \text { daily throughout } \\
\text { pregnancy. } \\
\text { Age } 30.8 \pm 2.2 \\
\text { BMI } 30.1 \pm 1.5 \text {. }\end{array}$ & $\begin{array}{l}160 \text { women } \\
\text { discontinued } \\
\text { metformin use at the } \\
\text { time of conception. } \\
\text { Age } 31.5 \pm 2.4 \\
\text { BMI } 29.6 \pm 1.6 \text {. }\end{array}$ & $\begin{array}{l}\text { Gestational diabetes, } \\
\text { preeclampsia, and } \\
\text { caesarean section rate. }\end{array}$ \\
\hline
\end{tabular}

274 pregnancies were randomly assigned to either metformin or placebo treatment. Criteria were (1) PCOS diagnosed according to the Rotterdam criteria, (2) age 18-45 yr, (3) gestational age between 5 and $12 \mathrm{wk}$, and (4) a singleton viable fetus shown on ultrasonography.
The metformin (2000 mg daily) treatment in pregnant PCOS women $(n=135)$.

Age $29.6 \pm 4.4$ BMI $29.5 \pm 7.0$.
Placebo in pregnant PCOS women $(n=$ 138).

Age $29.2 \pm 4.4$ BMI $28.5 \pm 7.2$.
Preeclampsia, preterm delivery, GDM weight, blood pressure, heart rate, and mode and length of delivery.
In 78 cases, metformin was stopped in first trimester or they conceived without 119 (cases) were taking metformin $500 \mathrm{mg}$ three times a 197 infertile obese Pakistani women with PCOS (Rotterdam 2003 consensus)

metformin.

21 conceived without medication, 13 conceived on day and continued throughout pregnancy.

70 conceived while on metformin only. 49 needed additional medications. Age $29 \pm 4.1$, BMI $32 \pm 4.6$. metformin, and 44 required induction of ovulation and metformin.

Age $26 \pm 5.3$

BMI $33.2 \pm 5.2$.

59 nondiabetic infertile PCOS (Rotterdam criteria) patients with clomiphene citrate (CC) resistance and insulin resistance were conceived while taking metformin and different ovulation-inducing agents.

\section{9 continued metformin} throughout pregnancy. $1500 \mathrm{mg}$ daily for $\mathrm{BMI} \leq 29$, $2000 \mathrm{mg}$ daily for BMI 30-32 and $2500 \mathrm{mg}$ daily for BMI $>32$. Age $28.14 \pm 2.92$, BMI $28.21 \pm$ 2.37 .

105 conceived while taking metformin.
137 infertile Pakistani women with PCOS (2003 Rotterdam Consensus criteria).

$\begin{array}{ll}28 & \text { and insulin resistance were } \\ & \text { conceived while taking metformin } \\ & \text { and different ovulation-inducing } \\ & \text { agents. }\end{array}$

criteria).

Group A (4-16 weeks met); group B (to 32 weeks met); group $\mathrm{C}$ (to delivery). Group A Group B Group C Age $28 \pm 3.629 \pm 3.127 \pm 4.2$

\section{BMI $29.6 \pm 5.130 \pm 2.629 .3 \pm 3.3$.}

30 did not continue metformin throughout pregnancy.

Age $26.13 \pm 3.62$, BMI $27.97 \pm 2.49$.
EPL (fetal loss before 12 weeks of gestation), gestational diabetes (GDM), and pregnancy induced hypertension (PIH), live births, intrauterine growth restriction (IUGR), and fetal anomalies.
40 pregnant women (Norway) with PCOS (revised 2003 consensus) and without known diabetes mellitus were included in the first trimester.
22 took metformin $850 \mathrm{mg}$ twice daily. Age $28.3 \pm 1.7$, BMI $29.3 \pm 3.6$.
18 with placebo. Age 28.9 \pm 2.5 , BMI $32.1 \pm 3.1$.
Abortion rate, development of GDM, live birth rate, congenital anomaly, macrosomia, and condition of newborn at birth. 
TABLE 2: Continued.

\begin{tabular}{|c|c|c|c|c|}
\hline Number & Population & Intervention & Comparison & Relevant outcomes \\
\hline 31 & $\begin{array}{l}\text { Nondiabetic women with PCOS } \\
\text { (2003 European Society of Human } \\
\text { Reproduction and } \\
\text { Embryology-American Society for } \\
\text { Reproductive Medicine diagnostic } \\
\text { criteria) }\end{array}$ & $\begin{array}{l}\text { Given } 26 \% \text { protein, } 44 \% \\
\text { carbohydrate diets, without } \\
\text { calorie restriction during } \\
\text { pregnancy, metformin } 2-2.55 \mathrm{~g} \\
\text { of metformin per day was taken } \\
\text { in } 120 \text { pregnancies: } 1700 \mathrm{mg} / \mathrm{d} \text { in } \\
6,1500 \mathrm{mg} \text { in } 39,1000 \mathrm{mg} / \mathrm{d} \text { in } 6 \text {, } \\
\text { and } 750 \mathrm{mg} / \mathrm{d} \text { in } 1 . \\
\text { Age } 30 \pm 5 \text {, BMI } 33.5 \pm 7.9 \text {. }\end{array}$ & $\begin{array}{l}47 \text { women had at least } \\
\text { one previous LB } \\
\text { pregnancy } \\
(n=64) \text { without } \\
\text { metformin. }\end{array}$ & $\begin{array}{l}\text { The primary outcome } \\
\text { measure was development } \\
\text { of GD. }\end{array}$ \\
\hline
\end{tabular}

40 pregnant women with PCOS

32 (Rotterdam ESHRE/ASRM sponsored PCOS workshop group, 2004).
18 women were randomized to metformin medication.

Age $28.9 \pm 4.8$, BMI $32.1 \pm 6.1$.
22 were placebo. Age $28.3 \pm 3.7$, BMI $39.3 \pm 8.0$.

Androgen levels, pregnancy complications (preterm deliveries, preeclampsia/hypertension GD, CS, and ARDS).

Infants (head circumference, birth-weight, birth-length, Apgar (5 min), and Apgar $(10 \mathrm{~min})$ ).

Gestational diabetes, number of first trimester $\mathrm{SAB}$, live births, normal ongoing pregnancies $\geq 13$ weeks, nature of

72 women from the midwestern USA who were referred to a 1-year study of efficacy and safety of metformin therapy in PCOS.
Conceived on metformin, $1.5-2.55 \mathrm{~g} /$ day. BMI $33 \pm 5.8$.

Self as control intrauterine fetal development by sonography, congenital defects, infant birth weight and height, and height, weight, and motor and social development during the first 6 months of life.

33 (32 white women and 1 Latina) nondiabetic women with PCOS who conceived while taking metformin and had live births; of these, 28 were taking metformin through delivery. Metformin, $2.55 \mathrm{~g} / \mathrm{d}$, throughout pregnancy in women with PCOS.
40 pregnant women with PCOS (revised 2003 consensus' diagnostic criteria of PCOS) were recruited from the outpatient clinic at the 35 University Hospital of Trondheim. All participants used two capsules once daily during the first week and two capsules twice daily for the rest of the pregnancy.
39 nondiabetic women with PCOS who had live birth pregnancies without metformin therapy.
Pretreatment height, weight, body mass index (BMI), glucose, insulin, insulin resistance and insulin secretion, and gestational diabetes.
Minor complications included mild preeclampsia, hypertension and/or insulin-treated GDM. Severe complications included
Treatment with metformin $425 \mathrm{mg}$ (at 6-12, mean 8, gestational weeks). Age $28.9 \pm 3.7$, BMI $32.1 \pm 6.1$.
Identical placebo capsules.

Age 28.3 \pm 3.7 ,

BMI $29.3 \pm 8.0$. preterm deliveries before 32 gestational weeks, severe preeclampsia, or serious postpartum problems (e.g., endometritis and Group A streptococcal sepsis, adult acute respiratory distress syndrome (ARDS), thrombosis, or lung embolism). 
TABLE 2: Continued.

\begin{tabular}{|c|c|c|c|c|}
\hline Number & Population & Intervention & Comparison & Relevant outcomes \\
\hline 36 & $\begin{array}{l}57 \text { infertile cases with PCOS } \\
\text { (revised } 2003 \text { consensus' diagnostic } \\
\text { criteria of PCOS) who became } \\
\text { pregnant and were in the infertility } \\
\text { unit and outpatient clinics in } \\
\text { Zagazig university hospitals }\end{array}$ & $\begin{array}{l}\text { Received metformin, starting in a } \\
\text { dose of } 1000 \text { mg daily increased } \\
\text { to } 2500 \mathrm{mg} \text { daily according to } \\
\text { BMI and response to treatment, } \\
\text { some cases used other ovulation } \\
\text { inducing drugs as clomiphene } \\
\text { citrate and or gonadotrophines. } \\
\text { When pregnancy occurred, cases } \\
\text { continued on metformin in a } \\
\text { dose of } 1000-1500 \text { mg daily till } \\
\text { the end of pregnancy } \\
\text { Age } 30.2 \pm 3.87 \text {, BMI } 29.22 \pm 2.31\end{array}$ & $\begin{array}{l}\text { Got pregnant } \\
\text { spontaneously or by } \\
\text { use of ovulation } \\
\text { inducing agents but did } \\
\text { not use metformin } \\
\text { before or after } \\
\text { pregnancy. } \\
\text { Age } 28.12 \pm 4.35, \text { BMI } \\
28.35 \pm 1.97\end{array}$ & $\begin{array}{l}\text { The rate of; spontaneous } \\
\text { miscarriage, preterm } \\
\text { delivery, fetal macrosomia, } \\
\text { intrauterine growth } \\
\text { restriction } \\
\text { (IUGR), suspected fetal } \\
\text { asphyxia at birth ( } 5 \text { min } \\
\text { Apgar } \\
\text { score } 67 \text { ) and recording of } \\
\text { congenital malformation } \\
\text { and neonatal mortality. }\end{array}$ \\
\hline
\end{tabular}

TABLE 3: Quality of the randomized controlled trials.

\begin{tabular}{|c|c|c|c|c|}
\hline \multirow{4}{*}{ Number } & \multirow{4}{*}{ Country } & $\begin{array}{l}\text { Allocation } \\
\text { concealment }\end{array}$ & Blinding & \multirow{4}{*}{ ITT } \\
\hline & & A: adequate & A: investigators & \\
\hline & & B: unclear & B: patients & \\
\hline & & C: inadequate & $\begin{array}{c}\text { C: outcome } \\
\text { assessors }\end{array}$ & \\
\hline 22 & $\begin{array}{l}\text { Norway } \\
\text { (2 RCTs) }\end{array}$ & A & $\begin{array}{l}\text { A: Yes } \\
\text { B: Yes } \\
\text { C: No }\end{array}$ & Yes \\
\hline 26 & $\begin{array}{c}\text { Norway } \\
\text { (multicenter } \\
\text { study) }\end{array}$ & A & $\begin{array}{l}\text { A: Yes } \\
\text { B: Yes } \\
\text { C: Yes }\end{array}$ & No \\
\hline 30 & Norway & A & $\begin{array}{c}\text { A: Yes } \\
\text { B: Yes } \\
\text { C: Not reported }\end{array}$ & No \\
\hline 32 & Norway & A & $\begin{array}{c}\text { A: Yes } \\
\text { B: Yes } \\
\text { C: Not reported }\end{array}$ & No \\
\hline 35 & Norway & A & $\begin{array}{c}\text { A: Yes } \\
\text { B: Yes } \\
\text { C: Not reported }\end{array}$ & No \\
\hline
\end{tabular}

ITT: intention-to-treat.

potential effect of metformin invention during the gestational period on gestational diabetes occurrence risk in patients with polycystic ovary syndrome.

Gestational diabetes mellitus (GDM) represents an important medical and social problem in the general pregnancy population, and it becomes harmful to the health of mother and fetus as well as neonate. Boomsma et al. [37] investigated that women with PCOS demonstrated a significantly higher risk of developing GDM (OR = $2.94)$, pregnancy-induced hypertension $(\mathrm{OR}=3.67)$, and preeclampsia $(\mathrm{OR}=3.47)$, and their babies had a significantly higher risk of admission to a neonatal intensive care unit $(\mathrm{OR}=2.31)$ and a higher perinatal mortality $(\mathrm{OR}=3.07)$. Thiebaugeorges et al. [38] has included that the traditional therapy in pregnancy for GDM includes the use of diet and exercise and/or insulin injection. Meanwhile, several researchers have already demonstrated that the administration of metformin throughout pregnancy may decrease miscarriage and improve pregnancy outcomes including GDM, preeclampsia, and preterm delivery [34, 39-44].

Although a population-based cohort research, a system review, and meta-analysis recently identified that the patients with PCOS are at higher risk for pregnancy complications $[45,46]$, moreover, unless metformin was recommended for treatment in pregnancy complications especially DM because of its characteristics of safety, effectiveness, and nonteratogenicity, they could not reach an agreement on its use in prevention or treatment of GDM, hyperinsulinemia, and hyperandrogenemia throughout the pregnancy in women with PCOS. In our knowledge, during the past several decades, the retrospective and nonrandomized studies have confirmed beneficial effects of metformin on pregnancy miscarriage and pregnancy complications, in particular GDM in women with PCOS, whereas the potential effect of metformin to pregnancy complications in women with PCOS has been explored in five randomized, placebo-controlled trials so far $[26,32]$. The studies suggested no statistical difference in the prevalence of gestational diabetes, preeclampsia, and preterm delivery between the metformin- and the placebo-treated groups. As a result, meta-analytical summaries of existing studies therefore are of importance to GDM in PCOS.

Although it yields a reassuring trend, this analysis exemplifies the need for more research on metformin to DM during pregnancy. It was our initial aim to identify all possible adverse pregnancy outcomes including miscarriage, minor anomalies, major malformations, intrauterine growth retardation, GDM, preterm delivery, live birth, caesarean section rate, or the characteristics of infants in particular the birthheight, birth-weight, APGAR in 1 or 5 or 10 minutes, and head circumference. However, we were limited to focusing mainly on the pregnancy complications on GDM because of the paucity of data and the paradoxical effect of metformin on GDM in PCOS.

Notwithstanding our data, metformin administered alone throughout the pregnancy, or at least during first trimester, or in combination with other infertility treatments for inducing ovulation in patients with PCOS seems to have significant effect on GDM prevention. In fact, our non-RCTs 
TABLE 4: Findings of the trials included in the meta-analysis.

\begin{tabular}{|c|c|c|c|c|c|c|}
\hline Number & \multirow{2}{*}{$\begin{array}{l}\text { Outcome } \\
\text { Second-trimester } \\
\text { miscarriage and delivery } \\
<\text { gestational week } 37+0\end{array}$} & \multicolumn{3}{|c|}{ PCOS with metformin } & Controls & \multirow[t]{2}{*}{ Metformin versus controls } \\
\hline \multirow[t]{3}{*}{22} & & $5 / 153$ & & & $18 / 159$ & \\
\hline & Preeclampsia & $12 / 153$ & & & $7 / 157$ & $P=0.24$ \\
\hline & New gestational diabetes & $27 / 142$ & & & $26 / 141$ & $P=0.90$ \\
\hline \multirow{3}{*}{25} & GDM & $8 / 200$ & & & $32 / 160$ & $\begin{array}{l}P<0.001, \mathrm{OR}=0.17,95 \% \\
\mathrm{CI}=0.07-0.37\end{array}$ \\
\hline & $\begin{array}{l}\text { Gestational hypertension } \\
\text { and/or preeclampsia }\end{array}$ & $6 / 200$ & & & $13 / 160$ & $\begin{array}{l}P=0.03, \mathrm{OR}=0.35,95 \% \mathrm{CI} \\
=0.13-0.94\end{array}$ \\
\hline & Caesarean section rate & $106 / 200$ & & & $96 / 160$ & $\begin{array}{l}P=0.18, \mathrm{OR}=0.75,95 \% \mathrm{CI} \\
=0.49-1.15\end{array}$ \\
\hline \multirow{7}{*}{26} & Preeclampsia & $10 / 135$ & & & $5 / 135$ & $\begin{array}{l}P=0.18, \mathrm{RD}=3.7 \%, 95 \% \\
\mathrm{CI}=-1.7-9.2\end{array}$ \\
\hline & Preterm delivery & $5 / 135$ & & & $11 / 135$ & $\begin{array}{l}P=0.12, \mathrm{RD}=-4.4 \%, 95 \% \\
\mathrm{CI}=-10.1-1.2\end{array}$ \\
\hline & GDM & $22 / 125$ & & & $21 / 124$ & $\begin{array}{l}P=0.87, \mathrm{RD}=0.8 \%, 95 \% \\
\mathrm{CI}=-8.6-10.2\end{array}$ \\
\hline & & & & & & $\mathrm{RD}$ (risk difference) \\
\hline & & $\leq 2500 \mathrm{~g}$ & $8 / 13$ & & $\leq 2500 \mathrm{~g}$ & \\
\hline & Weight & $2501-450$ & $0 \mathrm{~g} \quad 125$ & 135 & $2501-4500 \mathrm{~g} \quad 120 / 135$ & \\
\hline & & $>4500 \mathrm{~g}$ & $2 / 13$ & & $>4500 \mathrm{~g}$ & $P=0.32$ \\
\hline \multirow{7}{*}{27} & Length of delivery & $50.3 \pm 4.4$ & & & $50.0 \pm 2.5$ & $P=0.44$ \\
\hline & Miscarriage rate & $9 / 119$ & & & $23 / 78$ & $P<0.002$ \\
\hline & $\begin{array}{l}\text { EPL with recurrent } \\
\text { miscarriage }\end{array}$ & $2 / 16$ & & & $5 / 11$ & $P<0.001$ \\
\hline & Gestational diabetes & $12 / 119$ & & & $34 / 78$ & 0.0021 \\
\hline & $\mathrm{PIH}$ & $20 / 119$ & & & $35 / 78$ & $<0.002$ \\
\hline & IUGR & $20 / 119$ & & & $30 / 78$ & $<0.001$ \\
\hline & Live birth rate & $109 / 119$ & & & $55 / 78$ & $<0.001$ \\
\hline \multirow{8}{*}{28} & GDM & $1 / 29$ & & & $9 / 30$ & $\begin{array}{l}\mathrm{OR}=12,95 \% \mathrm{CI}= \\
6.20-18.08\end{array}$ \\
\hline & Abortion & $1 / 29$ & & & $1 / 30$ & \\
\hline & Macrosomia & $0 / 29$ & & & $4 / 30$ & \\
\hline & LBW (low birth weight) & $0 / 29$ & & & $0 / 30$ & \\
\hline & Birth asphyxia & $0 / 29$ & & & $5 / 30$ & \\
\hline & Neonatal death & $0 / 29$ & & & $1 / 30$ & \\
\hline & Preterm labor & $2 / 29$ & & & $3 / 30$ & \\
\hline & Birth weight & $2.79 \pm 0.1$ & & & $3 \pm 0.499$ & $P=0.016$ \\
\hline \multirow{9}{*}{29} & APGAR (5 min) & $10 \pm 00$ & & & $9.03 \pm 0.326$ & $P=0.006$ \\
\hline & & Group A & Group & B Group C & & \\
\hline & $\mathrm{PIH} /$ preeclampsia & $14 / 32$ & $6 / 18$ & $6 / 45$ & $8 / 26$ & $P=0.002$ \\
\hline & GDM & $15 / 32$ & $10 / 18$ & $13 / 45$ & $12 / 26$ & $P=0.968$ \\
\hline & IUGR & $7 / 32$ & $3 / 18$ & $1 / 45$ & $5 / 26$ & $P=0.026$ \\
\hline & Miscarriage & $8 / 40$ & $2 / 20$ & $0 / 45$ & $6 / 32$ & $P=0.006$ \\
\hline & Preterm delivery & $8 / 32$ & $5 / 18$ & $2 / 41$ & $5 / 26$ & $P=0.035$ \\
\hline & Live birth & $32 / 40$ & $18 / 20$ & $45 / 45$ & $26 / 32$ & $P=0.016$ \\
\hline & Mean birth weight & $2.67 \pm 0.9$ & $12.71 \pm$ & $0.892 .88 \pm 0.95$ & $2.9 \pm 1.1$ & $P=0.81$ \\
\hline
\end{tabular}


TABLE 4: Continued.

\begin{tabular}{|c|c|c|c|c|}
\hline Number & Outcome & PCOS with metformin & Controls & Metformin versus controls \\
\hline 30 & GDM & $6 / 22$ & $3 / 18$ & \\
\hline 31 & GDM & $6 / 50$ & $19 / 64$ & \\
\hline \multirow{9}{*}{32} & Preterm deliveries & $0 / 18$ & $5 / 22$ & \\
\hline & Preeclampsia/hypertension & $3 / 18$ & $2 / 22$ & \\
\hline & GDM & $1 / 18$ & $3 / 22$ & \\
\hline & CS (caesarean section) & $3 / 18$ & $4 / 22$ & \\
\hline & Head circumference & $36 \pm 1$ & $34 \pm 5$ & $P=0.07$ \\
\hline & Birth weight & $3595 \pm 420$ & $3215 \pm 1048$ & $P=0.1$ \\
\hline & Birth length & $50 \pm 2$ & $48 \pm 8$ & $P=0.2$ \\
\hline & Apgar (5 min) & $9.3 \pm 1.0$ & $9.5 \pm 0.6$ & $P=0.3$ \\
\hline & Apgar (10 min) & $9.8 \pm 0.7$ & $9.9 \pm 0.2$ & $P=0.3$ \\
\hline \multirow[t]{2}{*}{33} & $\begin{array}{l}\text { SAB (first-trimester } \\
\text { spontaneous abortion) }\end{array}$ & $12 / 46$ & $62 / 100$ & $\begin{array}{l}\text { McNemar's }=32, \mathrm{df}=1, P< \\
0.0001\end{array}$ \\
\hline & GDM & $3 / 68$ & $9 / 34$ & McNemar's $=5, P=0.025$ \\
\hline 34 & GDM & $1 / 33$ & $10 / 37$ & $P=0.0074$ (Fisher test $)$ \\
\hline \multirow{6}{*}{35} & GDM & $2 / 18$ & $6 / 22$ & $P=0.3$ \\
\hline & $\begin{array}{l}\text { Overall pregnancy } \\
\text { complications }\end{array}$ & $3 / 18$ & $10 / 22$ & $P=0.09$ \\
\hline & $\begin{array}{l}\text { Severe pregnancy } \\
\text { complications }\end{array}$ & $0 / 18$ & $7 / 22$ & $P=0.01$ \\
\hline & Miscarriage & $1 / 31$ & $7 / 26$ & $P=0.01$ \\
\hline & Preterm birth & $1 / 31$ & $2 / 26$ & $P=0.58$ \\
\hline & Fatal macrosomia & $1 / 31$ & $1 / 26$ & $P=1.0$ \\
\hline \multirow[t]{5}{*}{36} & IUGR & $0 / 31$ & $1 / 26$ & $P=0.45$ \\
\hline & 5 min Apgar score $(\leq 7)$ & $1 / 31$ & $3 / 26$ & $P=0.32$ \\
\hline & Fatal anomalies & $0 / 31$ & $1 / 26$ & $P=0.45$ \\
\hline & Neonatal mortality & $0 / 31$ & $1 / 26$ & $P=0.45$ \\
\hline & GDM & $1 / 31$ & $6 / 26$ & \\
\hline
\end{tabular}

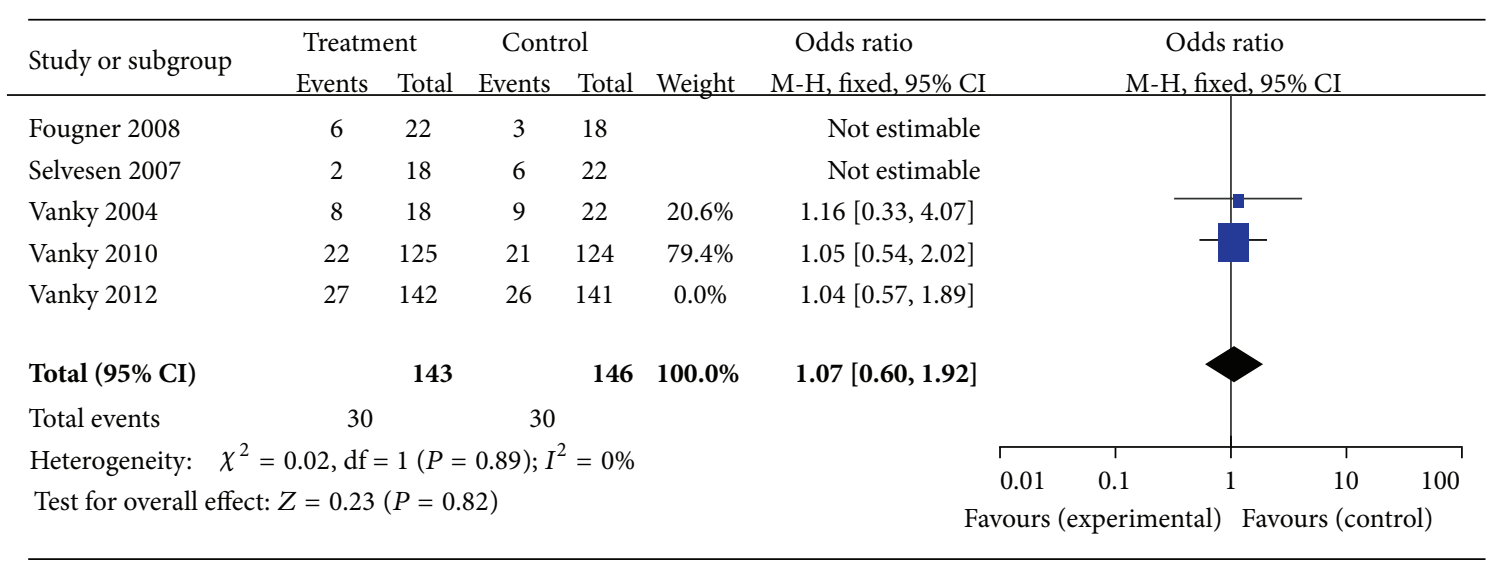

FIGURE 2: The meta-analysis of the odds ratio for gestational diabetes in RCTs.

data demonstrated reduction of GDM occurrence risk in patients who received metformin in comparison with those who did not, for an overall relative risk for GDM of 0.19 (95\% CI, 0.13-0.27). These findings were also confirmed by categorizing studies according to the objects control.
Nevertheless, on the basis of RCT studies available now, metformin does not appear to be unavailable for use during pregnancy with respect to diabetes mellitus, for an overall relative risk for GDM of 1.07 (95\% CI, 0.60-1.92). As with placebo use in pregnancy, it is challenging to establish the 


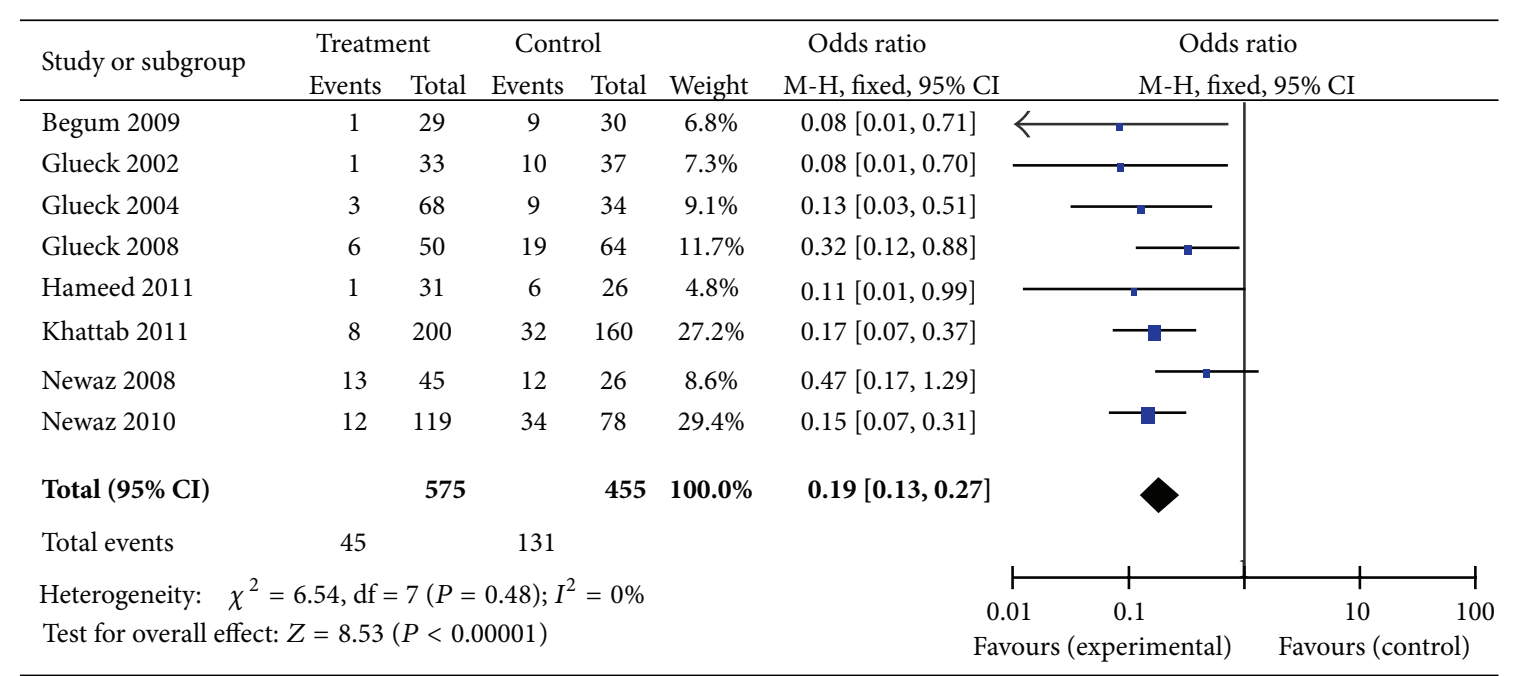

FIGURE 3: The meta-analysis of the odds ratio for gestational diabetes in the studies with disease-matched controls or patients' selves as control.

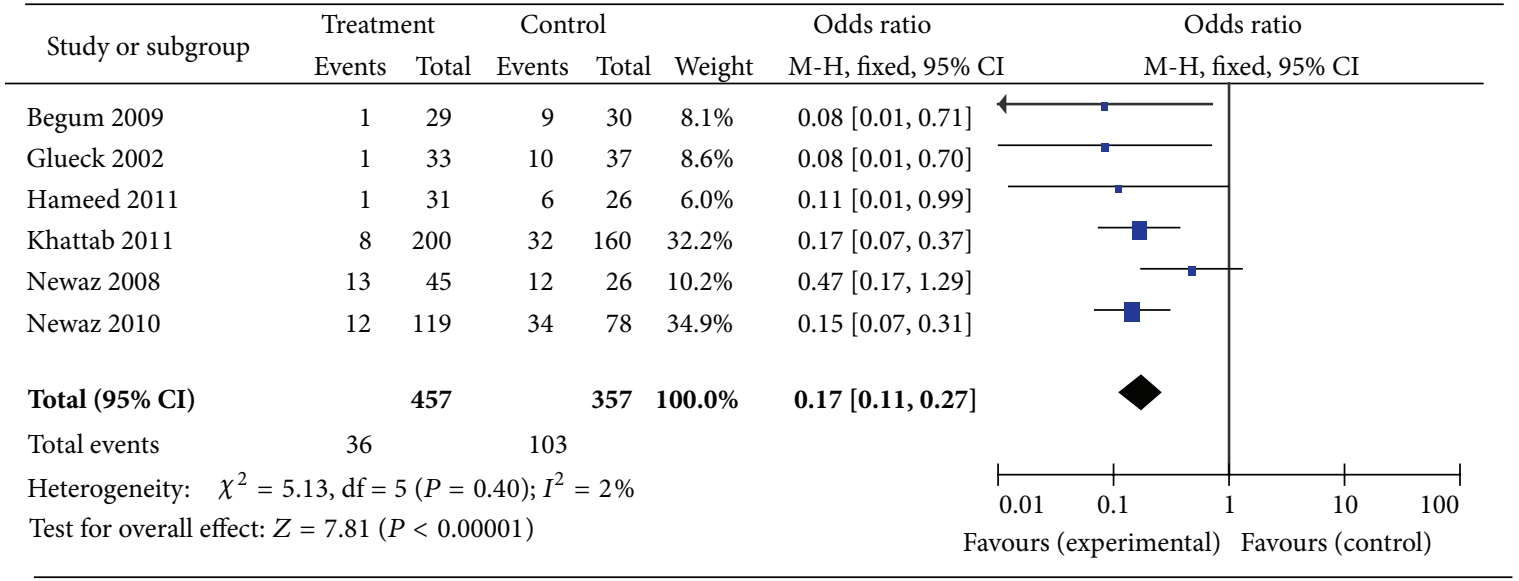

FIgURE 4: The meta-analysis of the odds ratio for gestational diabetes in the studies with PCOS as control.

necessity of metformin use in pregnancy considering the background incidence of diabetes in the confounder of the underlying diseases with PCOS that have been linked to increased rates of diabetes.

However, it is not always true that RCTs and nonRCTs arrive at the same conclusions and, consequently, it is important to ask what should be done when they do not agree. First of all, the evidence of data derived from multiple randomized clinical trials or meta-analyses is stronger than data derived from a single randomized trial or unrandomized studies [47]. Thus, if a RCT study differs from several nonRCTs, then there is a pressing need to identify the studies much more deeply. We examine the possible reasons why two types of studies arrived at different conclusions and the potential threats to validity of observational outcomes and RCTs. Our analysis and review indicate that several methodological issues are relevant because they may affect the interpretation of some of the studies published on GDM. Most of the studies were retrospective or prospective of cohorts or case-control studies or observation researches and conducted at single center or multiple centers, and many studies included a small number of women, or else, the five RCTs, including the three studies of the same research object and one study epianalyzing the other two trials, took place in the same country as Norway and the study group of patients mainly recruited from the near clinic center imposed the restrictions on the outcomes, and thus the current situation limited the validity of the results. The second factors of different conclusion may be selection bias. Perhaps the most serious advantages of RCT are blindness and randomization because there may be large observed and unobserved differences in patients between the treatment and control groups [48]. These differences may explain why our meta-analysis concludes different results of RCTs and nonRCTs as RCTs were developed for the purpose of eliminating this bias.

During pregnancy, extra care must be taken to ensure the safety of the fetus or neonates. Our meta-analytical summary and review of inclusive studies therefore have indicated monitoring metformin safety. Although all included 


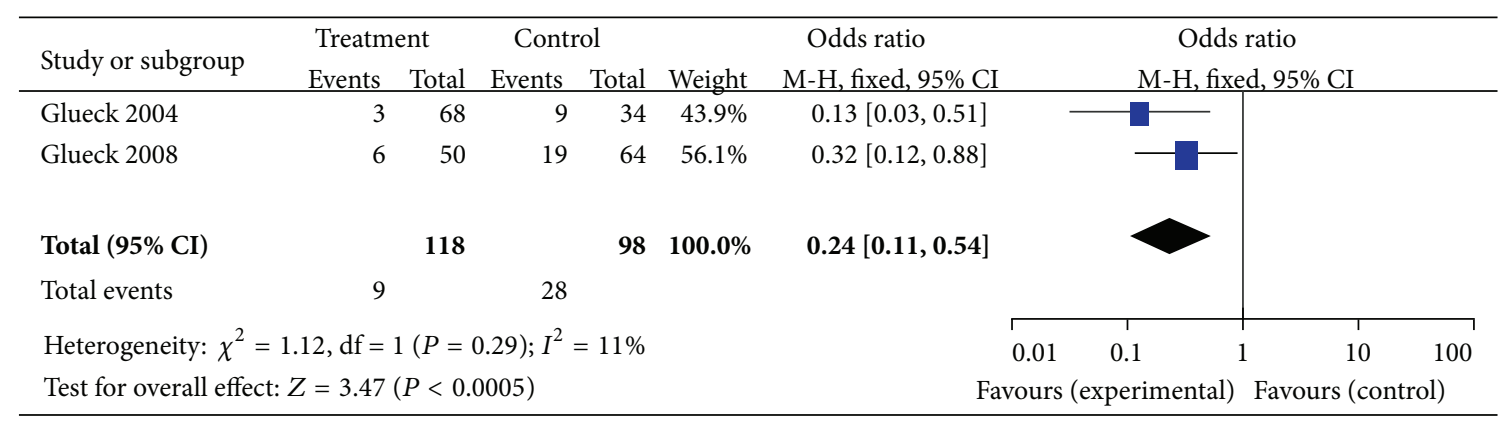

FIGURE 5: The meta-analysis of the odds ratio for gestational diabetes in the studies with patients' selves as control.

studies are very heterogeneous for protocols and doses of the drug administered and for characteristics of the studied populations, the detected observation of the results, such as lactic acidosis, birth defects, and maternal or neonatal hypoglycemia, is just a case-report and has no statistical analytical significance.

Our systematic review and meta-analysis of RCTs studies demonstrates no statistically significant benefit of metformin administration on the DM risk in PCOS patients who received the drug as monotherapy. However, we examine that non-RCTs have a characteristic of a lower GDM occurrence rate in the metformin group compared with the PCOSmatched control group. Thus, at the moment, there is no clinical evidence to suggest that metformin administration reduces the risk of diabetes in women with PCOS.

\section{Conclusion}

Metformin is an effective insulin sensitizer treating type 2 diabetes mellitus. However, the functional consequences of metformin administration throughout pregnancy on gestational diabetes mellitus (GDM) have not been assessed. Metformin has been increasingly regarded to be effective and safe medicine for the metabolic and endocrine abnormalities in PCOS. In our knowledge, this is the first systematic review and meta-analysis of trials including RCTs performed to establish the potential effect of metformin intervention during the gestational period on gestational diabetes occurrence risk in patients with polycystic ovary syndrome. We therefore performed a meta-analysis and system review to determine the effect of metformin on GDM in patients with PCOS. A meta-analysis was performed on the published studies before December, 2013. Meta-analysis examined whether metformin could reduce GDM occurrence in PCOS with a fixed effect model. The odds ratio (OR) with $95 \%$ confidence interval $(95 \% \mathrm{CI})$ was calculated to estimate the strength of association. A total of 13 studies including five RCTs and eight non-RCTs were enrolled. Ultimately, effectiveness analysis demonstrated that, in total, there was no significant availability of metformin on GDM in PCOS in contrast to placebo $(\mathrm{OR}=1.07,95 \% \mathrm{CI} 0.60-1.92)$ in RCTs and significant availability of metformin on GDM (OR $=0.19$, 95\% CI 0.13-0.27) was indicated in non-RCTs. Subanalysis was conducted to separate studies into those with PCOS and those with patients' selves with PCOS subjects as controls. With 457 subjects in the treatment group, the OR for the non-diabetes pregnancy subjects group was 0.17 (95\% CI, $0.11-0.28$ ). With 118 subjects in the treatment group for PCOS with self as control, the OR was 0.24 (95\% CI, 0.11-0.54). In summary, according to the results of our meta-analysis, strictly, metformin did not significantly have effect on GDM with PCOS, though more multicenters RCTs still need to be investigated. Thus, at the moment, there is no clinical evidence to suggest that metformin administration reduces the risk of diabetes in women with PCOS.

\section{Conflict of Interests}

The authors declare that there is no conflict of interests regarding the publication of this paper.

\section{References}

[1] J. E. Nestler, D. J. Jakubowicz, W. S. Evans, and R. Pasquali, "Effects of metformin on spontaneous and clomiphene-induced ovulation in the polycystic ovary syndrome," The New England Journal of Medicine, vol. 338, no. 26 I, pp. 1876-1880, 1998.

[2] E. M. Velazquez, S. G. Mendoza, T. Hamer, F. Sosa, and C. J. Glueck, "Metformin therapy in polycystic ovary syndrome reduces hyperinsulinemia, insulin resistance, hyperandrogenemia, and systolic blood pressure, while facilitating normal menses and pregnancy," Metabolism: Clinical and Experimental, vol. 43, no. 5, pp. 647-654, 1994.

[3] E. Diamanti-Kandarakis, C. Kouli, T. Tsianateli, and A. Bergiele, "Therapeutic effects of metformin on insulin resistance and hyperandrogenism in polycystic ovary syndrome," European Journal of Endocrinology, vol. 138, no. 3, pp. 269-274, 1998.

[4] C. J. Glueck, P. Wang, R. Fontaine, T. Tracy, and L. Sieve-Smith, "Metformin-induced resumption of normal menses in 39 of 43 (91\%) previously amenorrheic women with the polycystic ovary syndrome," Metabolism: Clinical and Experimental, vol. 48, no. 4, pp. 511-519, 1999.

[5] P. Moghetti, R. Castello, C. Negri et al., "Metformin effects on clinical features, endocrine and metabolic profiles, and insulin sensitivity in polycystic ovary syndrome: a randomized, doubleblind, placebo-controlled 6-month trial, followed by open, long-term clinical evaluation," Journal of Clinical Endocrinology and Metabolism, vol. 85, no. 1, pp. 139-146, 2000. 
[6] L. C. Morin-Papunen, R. M. Koivunen, A. Ruokonen, and H. K. Martikainen, "Metformin therapy improves the menstrual pattern with minimal endocrine and metabolic effects in women with polycystic ovary syndrome," Fertility and Sterility, vol. 69, no. 4, pp. 691-696, 1998.

[7] E. Velázquez M., A. Acosta, and S. G. Mendoza, "Menstrual cyclicity after metformin therapy in polycystic ovary syndrome," Obstetrics and Gynecology, vol. 90, no. 3, pp. 392-395, 1997.

[8] E. M. Velazquez, S. G. Mendoza, P. Wang, and C. J. Glueck, "Metformin therapy is associated with a decrease in plasma plasminogen activator inhibitor-1, lipoprotein(a), and immunoreactive insulin levels in patients with the polycystic ovary syndrome," Metabolism: Clinical and Experimental, vol. 46, no. 4, pp. 454-457, 1997.

[9] V. De Leo, A. La Marca, and F. Petraglia, "Insulin-lowering agents in the management of polycystic ovary syndrome," Endocrine Reviews, vol. 24, no. 5, pp. 633-667, 2003.

[10] A. Dunaif, K. R. Segal, W. Futterweit, and A. Dobrjansky, "Profound peripheral insulin resistance, independent of obesity, in polycystic ovary syndrome," Diabetes, vol. 38, no. 9, pp. 1165$1174,1989$.

[11] S. Franks, S. Robinson, and D. S. Willis, "Nutrition, insulin and polycystic ovary syndrome," Reviews of Reproduction, vol. 1, no. 1, pp. 47-53, 1996.

[12] D. Willis, H. Mason, C. Gilling-Smith, and S. Franks, "Modulation by insulin of follicle-stimulating hormone and luteinizing hormone actions in human granulosa cells of normal and polycystic ovaries," Journal of Clinical Endocrinology and Metabolism, vol. 81, no. 1, pp. 302-309, 1996.

[13] A. J. Krentz and C. J. Bailey, "Oral antidiabetic agents: current role in type 2 diabetes mellitus," Drugs, vol. 65, no. 3, pp. 385411, 2005.

[14] S. A. Raptis and G. D. Dimitriadis, "Oral hypoglycemic agents: insulin secretagogues, $\alpha$-glucosidase inhibitors and insulin sensitizers," Experimental and Clinical Endocrinology and Diabetes, vol. 109, no. 2, pp. S265-S287, 2001.

[15] R. S. Hundal, M. Krssak, S. Dufour et al., "Mechanism by which metformin reduces glucose production in type 2 diabetes," Diabetes, vol. 49, no. 12, pp. 2063-2069, 2000.

[16] C. J. Bailey and R. C. Turner, "Metformin," The New England Journal of Medicine, vol. 334, no. 9, pp. 574-579, 1996.

[17] M. A. Checa, A. Requena, C. Salvador et al., "Insulin-sensitizing agents: use in pregnancy and as therapy in polycystic ovary syndrome," Human Reproduction Update, vol. 11, no. 4, pp. 375390, 2005.

[18] E. David, "Poly cystic ovarian syndrome," The New England Journal of Medicine, vol. 352, pp. 1223-1236, 2005.

[19] B. Charles, R. Norris, X. Xiao, and W. Hague, "Population pharmacokinetics of metformin in late pregnancy," Therapeutic Drug Monitoring, vol. 28, no. 1, pp. 67-72, 2006.

[20] E. Vanky, K. Zahlsen, O. Spigset, and S. M. Carlsen, "Placental passage of metformin in women with polycystic ovary syndrome," Fertility and Sterility, vol. 83, no. 5, pp. 1575-1578, 2005.

[21] J. E. L. Goh, L. Sadler, and J. Rowan, "Metformin for gestational diabetes in routine clinical practice," Diabetic Medicine, vol. 28, no. 9, pp. 1082-1087, 2011.
[22] E. Vanky, D. E. Zegher F, M. Díaz et al., "On the potential of metformin to prevent preterm delivery in women with polycystic ovary syndrome-an epi-analysis," Acta Obstetricia et Gynecologica Scandinavica, vol. 91, no. 12, pp. 1460-1464, 2012.

[23] J. P. T. Higgins and S. Green, "Cochrane handbook for systematic reviews of interventions version 5.1.0. The Cochrane Collaboration," 2011, http://handbook.cochrane.org/.

[24] Cochrane Menstrual Disorders and Subfertility Group, Resources for review authors. Available at, http://mdsg. cochrane.org/resources-review-authors/.

[25] S. Khattab, I. A. Mohsen, I. Aboul Foutouh et al., "Can metformin reduce the incidence of gestational diabetes mellitus in pregnant women with polycystic ovary syndrome? Prospective cohort study," Gynecological Endocrinology, vol. 27, no. 10, pp. 789-793, 2011.

[26] E. Vanky, S. Stridsklev, R. Heimstad et al., "Metformin Versus placebo from first trimester to delivery in polycystic ovary syndrome: a randomized, controlled multicenter study," Journal of Clinical Endocrinology and Metabolism, vol. 95, no. 12, pp. E448-E455, 2010.

[27] F. H. Nawaz and J. Rizvi, "Continuation of metformin reduces early pregnancy loss in obese pakistani women with polycystic ovarian syndrome," Gynecologic and Obstetric Investigation, vol. 69, no. 3, pp. 184-189, 2010.

[28] M. R. Begum, N. N. Khanam, E. Quadir et al., "Prevention of gestational diabetes mellitus by continuing metformin therapy throughout pregnancy in women with polycystic ovary syndrome," Journal of Obstetrics and Gynaecology Research, vol. 35, no. 2, pp. 282-286, 2009.

[29] F. H. Nawaz, R. Khalid, T. Naru, and J. Rizvi, "Does continuous use of metformin throughout pregnancy improve pregnancy outcomes in women with polycystic ovarian syndrome?" Journal of Obstetrics and Gynaecology Research, vol. 34, no. 5, pp. 832-837, 2008.

[30] K. J. Fougner, E. Vanky, and S. M. Carlsen, "Metformin has no major effects on glucose homeostasis in pregnant women with PCOS: results of a randomized double-blind study," Scandinavian Journal of Clinical and Laboratory Investigation, vol. 68, no. 8, pp. 771-776, 2008.

[31] C. J. Glueck, J. Pranikoff, D. Aregawi, and P. Wang, "Prevention of gestational diabetes by metformin plus diet in patients with polycystic ovary syndrome," Fertility and Sterility, vol. 89, no. 3, pp. 625-634, 2008.

[32] E. Vanky, K. Å. Salvesen, R. Heimstad, K. J. Fougner, P. Romundstad, and S. M. Carlsen, "Metformin reduces pregnancy complications without affecting androgen levels in pregnant polycystic ovary syndrome women: results of a randomized study," Human Reproduction, vol. 19, no. 8, pp. 1734-1740, 2004.

[33] C. J. Glueck, N. Goldenberg, P. Wang, M. Loftspring, and A. Sherman, "Metformin during pregnancy reduces insulin, insulin resistance, insulin secretion, weight, testosterone and development of gestational diabetes: prospective longitudinal assessment of women with polycystic ovary syndrome from preconception throughout pregnancy," Human Reproduction, vol. 19, no. 3, pp. 510-521, 2004.

[34] C. J. Glueck, P. Wang, N. Goldenberg, and L. Sieve-Smith, "Pregnancy outcomes among women with polycystic ovary syndrome treated with metformin," Human Reproduction, vol. 17 , no. 11, pp. 2858-2864, 2002. 
[35] K. A. Salvesen, E. Vanky, and S. M. Carlsen, "Metformin treatment in pregnant women with polycystic ovary syndrome-is reduced complication rate mediated by changes in the uteroplacental circulation?" Ultrasound in Obstetrics and Gynecology, vol. 29, no. 4, pp. 433-437, 2007.

[36] A. A. Abd El Hameed, H. E. Shreif, and H. E. Mowafy, "The role of continuing metformin therapy during pregnancy in the reduction of gestational diabetes and improving pregnancy outcomes in women with polycystic ovary syndrome," Middle East Fertility Society Journal, vol. 16, pp. 204-208, 2011.

[37] C. M. Boomsma, M. J. C. Eijkemans, E. G. Hughes, G. H. A. Visser, B. C. J. M. Fauser, and N. S. Macklon, "A metaanalysis of pregnancy outcomes in women with polycystic ovary syndrome," Human Reproduction Update, vol. 12, no. 6, pp. 673683, 2006.

[38] O. Thiebaugeorges and B. Guyard-Boileau, "Obstetrical care in gestational diabetes and management of preterm labour," Diabetes \& Metabolism, vol. 36, no. 6, pp. 672-681, 2010.

[39] C. J. Glueck, P. Wang, S. Kobayashi, H. Phillips, and L. SieveSmith, "Metformin therapy throughout pregnancy reduces the development of gestational diabetes in women with polycystic ovary syndrome," Fertility and Sterility, vol. 77, no. 3, pp. 520$525,2002$.

[40] C. J. Glueck, S. Bornovali, J. Pranikoff, N. Goldenberg, S. Dharashivkar, and P. Wang, "Metformin, pre-eclampsia, and pregnancy outcomes in women with polycystic ovary syndrome," Diabetic Medicine, vol. 21, no. 8, pp. 829-836, 2004.

[41] M. Kocak, E. Caliskan, C. Simsir, and A. Haberal, "Metformin therapy improves ovulatory rates, cervical scores, and pregnancy rates in clomiphene citrate-resistant women with polycystic ovary syndrome," Fertility and Sterility, vol. 77, no. 1, pp. 101-106, 2002.

[42] L. Harborne, R. Fleming, H. Lyall, J. Norman, and N. Sattar, "Descriptive review of the evidence for the use of metformin in polycystic ovary syndrome," The Lancet, vol. 361, no. 9372, pp. 1894-1901, 2003.

[43] V. Bruni, M. Dei, V. Pontello, and P. Vangelisti, "The management of polycystic ovary syndrome," Annals of the New York Academy of Sciences, vol. 997, pp. 307-321, 2003.

[44] C. J. Glueck, H. Phillips, D. Cameron, L. Sieve-Smith, and P. Wang, "Continuing metformin throughout pregnancy in women with polycystic ovary syndrome appears to safely reduce first-trimester spontaneous abortion: a pilot study," Fertility and Sterility, vol. 75, no. 1, pp. 46-52, 2001.

[45] L. E. Kjerulff, L. Sanchez-Ramos, and D. Duffy, "Pregnancy outcomes in women with polycystic ovary syndrome: a metaanalysis," American Journal of Obstetrics and Gynecology, vol. 204, no. 6, pp. 558.e1-558.e6, 2011.

[46] N. Roos, H. Kieler, L. Sahlin, G. Ekman-Ordeberg, H. Falconer, and O. Stephansson, "Risk of adverse pregnancy outcomes in women with polycystic ovary syndrome: population based cohort study," British Medical Journal, vol. 343, Article ID d6309, 2011.

[47] E. L. Hannan, "Randomized clinical trials and observational studies guidelines for assessing respective strengths and limitations," JACC: Cardiovascular Interventions, vol. 1, no. 3, pp. 211217, 2008.

[48] N. Black, "Why we need observational studies to evaluate the effectiveness of health care," British Medical Journal, vol. 312, no. 7040, pp. 1215-1218, 1996. 


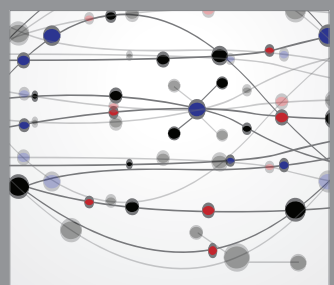

The Scientific World Journal
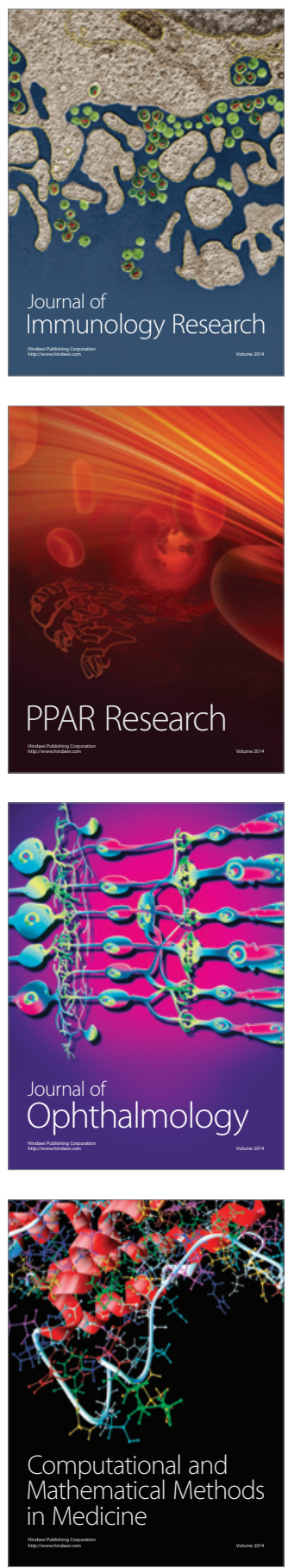

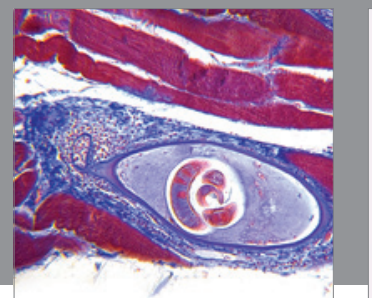

Gastroenterology

Research and Practice
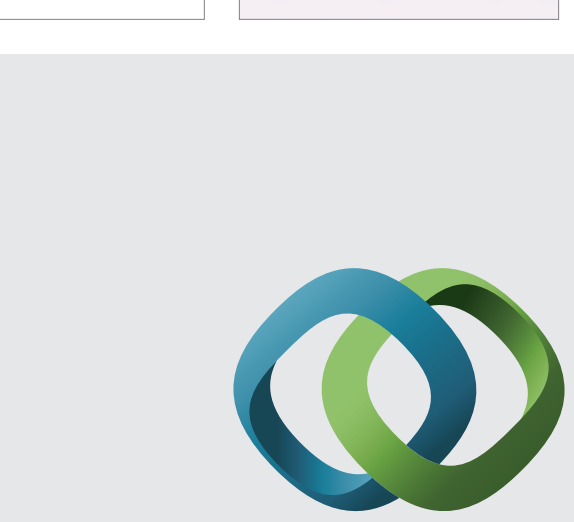

\section{Hindawi}

Submit your manuscripts at

http://www.hindawi.com
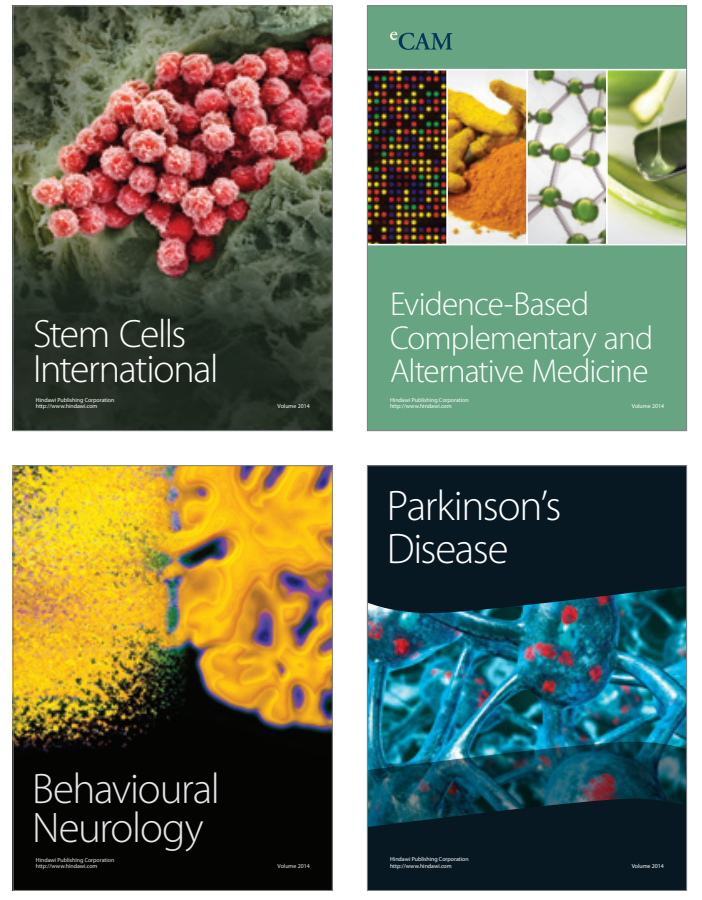
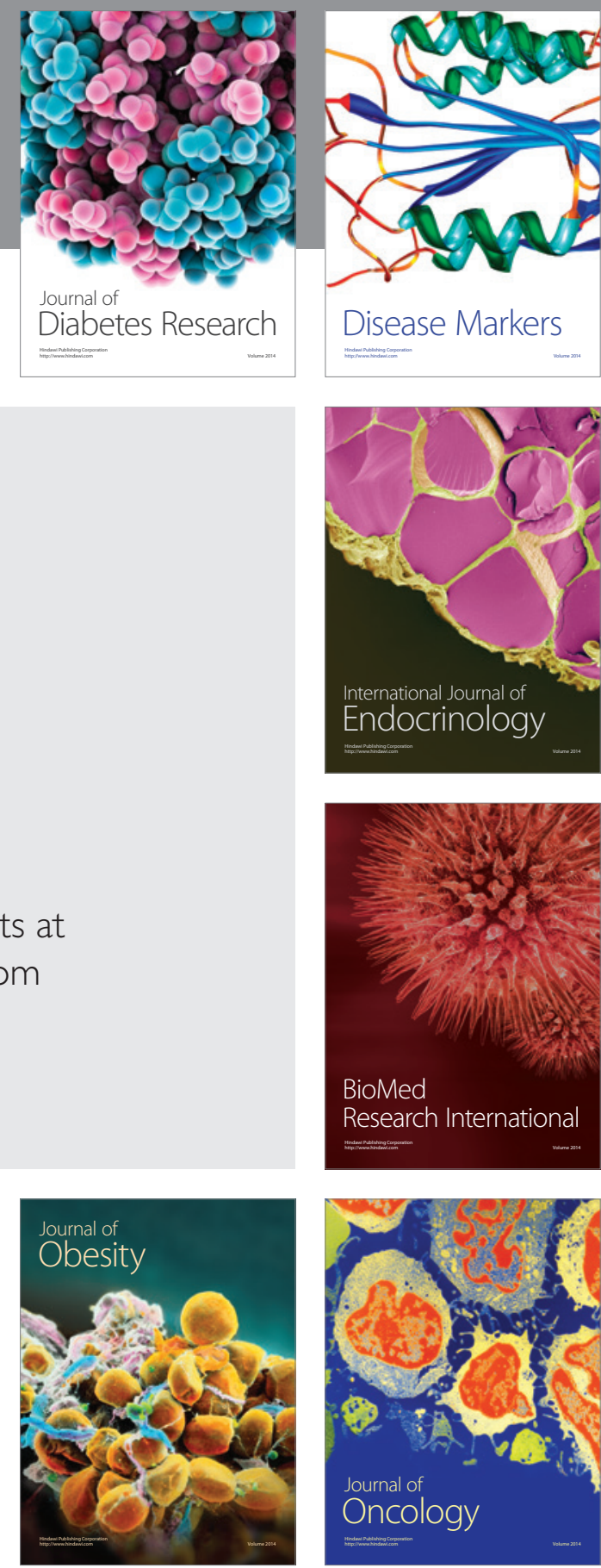

Disease Markers
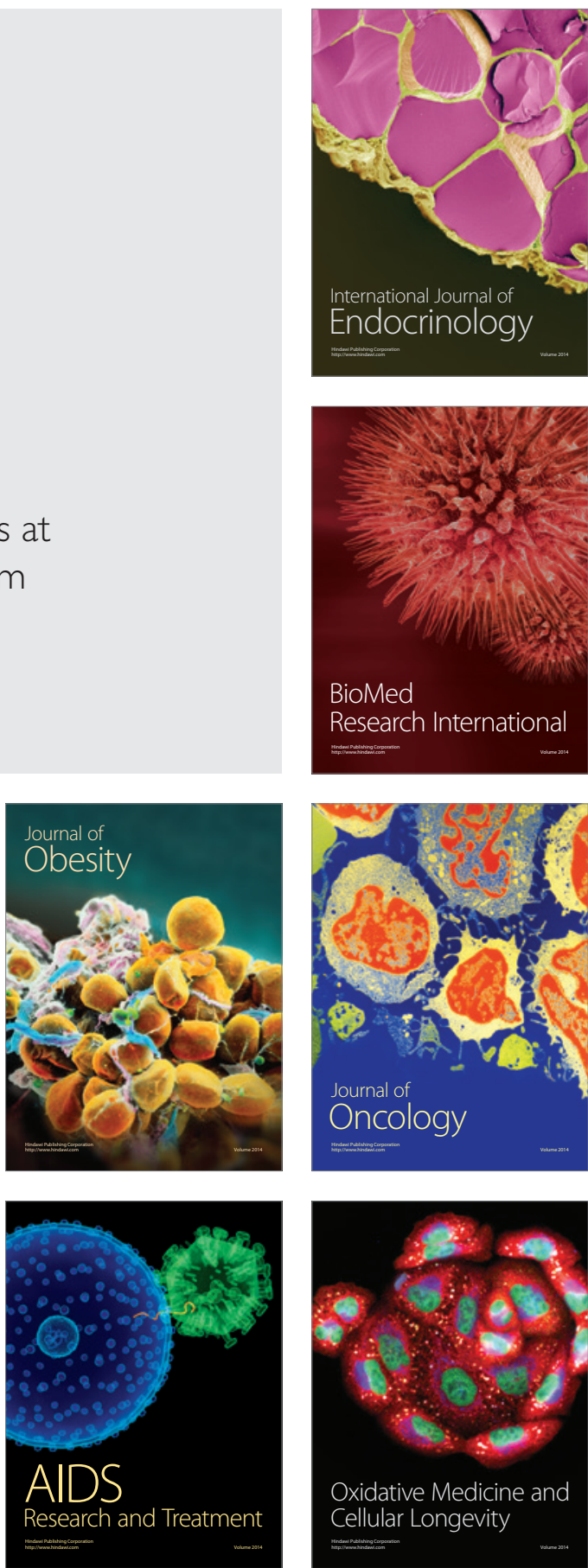